\title{
Behaviour of hybrid concrete columns under axial compression loads
}

\author{
Ali Resheq ${ }^{*}$ \\ Building and Construction Engineering Department, University of Technology, Baghdad, Iraq
}

\begin{abstract}
Hybrid Concrete Column (HCC) is composite column consists of two types of concrete, Normal Concrete (NC) and Self Compacted Concrete (SCC). The main objective of this work is to study the effect of outer to inner diameter ratio of hybrid concrete on the ultimate strength of column under the axial loading. Ten scaled columns (150 mm diameter and $600 \mathrm{~mm}$ length) were fabricated and cast with different ratio of $\mathrm{NC}$ to SCC and tested under axial loading. The test results were presented in term of loading and the axial and lateral strains at mid span of column length. It was found that the ultimate strength of column increased from $281 \mathrm{kN}$ to $605 \mathrm{kN}(215 \%)$. Also it was found that the strength of column increased when the SCC is in inner thickness rather than in outer thickness of the column and the strength increased with increasing the inner thickness of SCC.
\end{abstract}

\section{Introduction}

Hybrid concrete columns can be defined as a compression member consisting of composite SCC and NC. Hybrid columns have been used to carry high loading with small cross section area as an alternative to ordinary reinforced concrete during the past decades. Concrete columns can be reinforced by wound composites, which are providing circumferential confinements forces as well as higher compressive strength $[1,2]$. In last years, using of self compacting concrete SCC gave the structural engineers very favourably. Due to SCC properties many advantages mentioned and developed structural applications can be realizing. Elchalakani, et. Al. was reported that CFDSST column has almost the same advantage as normal CFST member. It has lighter weight, higher bending stiffness's and has best cyclic performances [3]. Tomii found that the axial loads capacity of concrete filling steel tube was better than the nominal capacity, which defined as the total of compressive strength of the unconfined steel and concrete [4]. Wei et. al., was verify the nominal strength of CFDSST column got from experimental work. He had find that the confinement effect of inner and outer tube, the strength from experimental tests are greater than the numerical as shown in figure (1). [5].

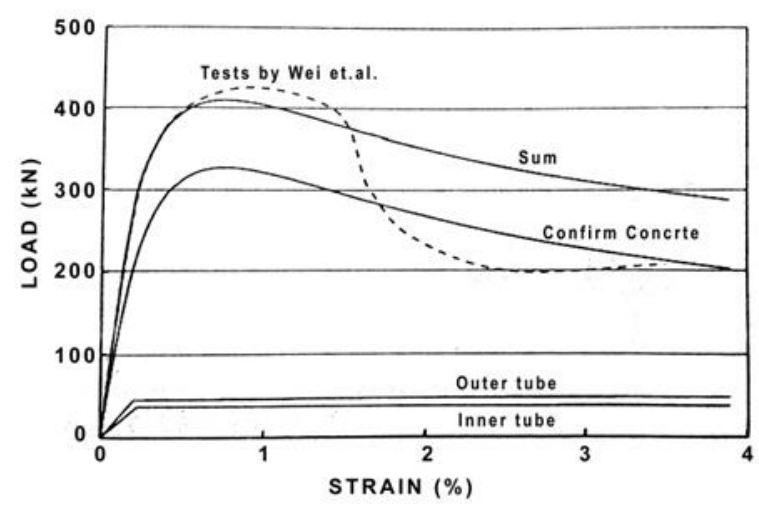

Fig. 1. The Comparison between analysis and test results of strength for CFSSDT column, [5].

\section{Experimental works}

The main objective of this experimental work is preparing and testing $10 \mathrm{HCC}$ columns divided to two groups having different ratio of SCC to $\mathrm{NC}$ as inner and outer cross section area. Both groups were tested under axial loading. All columns have same length $600 \mathrm{~mm}$ and same outer diameter $150 \mathrm{~mm}$ and the inner diameter was changed between NC and SCC. Table (1) and Figure (5) show the details of the specimens. 
Table 1. HC specimen Details.

\begin{tabular}{|c|c|c|c|c|c|}
\hline $\begin{array}{l}\text { Oे } \\
\text { O̊̉ }\end{array}$ & no. & $\begin{array}{l}\text { Column } \\
\text { designation }\end{array}$ & 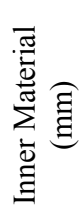 & 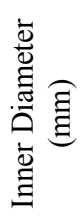 & 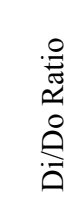 \\
\hline \multirow{5}{*}{1} & 1 & C-NC150-SCC0 & $\mathrm{NC}$ & 150 & 1 \\
\hline & 2 & C-NC125-SCC25 & $\mathrm{NC}$ & 125 & 0.83 \\
\hline & 3 & C-NC100-SCC50 & $\mathrm{NC}$ & 100 & 0.67 \\
\hline & 4 & C-NC75-SCC75 & $\mathrm{NC}$ & 75 & 0.5 \\
\hline & 5 & C-NC50-SCC100 & $\mathrm{NC}$ & 50 & 0.33 \\
\hline \multirow{5}{*}{2} & 6 & C-SCC50-NC100 & SCC & 50 & 0.33 \\
\hline & 7 & C-SCC75-NC75 & $\mathrm{SCC}$ & 75 & 0.5 \\
\hline & 8 & C-SCC100-NC50 & $\mathrm{SCC}$ & 100 & 0.67 \\
\hline & 9 & C-SCC125-NC25 & $\mathrm{SCC}$ & 125 & 0.83 \\
\hline & 10 & $\mathrm{C}-\mathrm{SCC} 150-\mathrm{NC} 0$ & SCC & 150 & 1 \\
\hline
\end{tabular}

Where,

C: Column

NC: Normal Concrete

SCC: Self Compacting Concrete.

Di: Inner Diameter.

Do: Outer Diameter $(\mathrm{Do}=150 \mathrm{~mm})$.

\section{Materials}

\subsection{Cement}

Ordinary Portland cement was used in the experimental works, the chemical composition and physical properties are tested and found comply with the Iraqi Specifications Standards Specifications IQS No.5/1984[6].

\subsection{Fine aggregate}

Natural Sands brought from Al-Akhaider Zone was used in concrete mixes. The fine aggregate had fineness modulus of (2.78) and shaped rounded and smooth texture. The lab results showed that fine aggregate is within Iraqi Specifications Standards Specifications IQS No.5/1984[6] and ASTM C33 specification [7].

\subsection{Course aggregate}

Crushed gravel of Al-Nibay Zone was used in this experimental works. The lab results showed that Course aggregate is within Iraqi Specifications Standards Specifications IQS No.5/1984[6] and ASTM C33 specification [7].

\subsection{Water}

Ordinary tap water was used for both mixes and curing of all specimens used in this experimental work. It was free from oil and organic material.

\subsection{Limestone powder (LSP)}

This material is a white grinding material coming from lime stone in the north of Iraq, usually used for the construction process and as filler of concrete production. Fine limestone powder was used in this experimental work, grinded by bowling technical. Size of particles of the limestone powder was less than $125 \times 10-3 \mathrm{~mm}$, and it was conformed to EFNARC [8].

\subsection{Superplasticizer}

Sulphated Melamine Formaldehyde (SMF) was used in this experimental works. (SMF) was free from chlorides and comply with ASTM C494 [9].

\section{Mixing procedure for NC and SCC}

\subsection{Normal concrete NC}

The laboratory mixing used in this work was according to Neville [10] for Normal Concrete. Table (2) presents the quantities by weight for material used per cubic meter of this mix.

Table 2. Mix Properties for $\mathrm{NC} / \mathrm{m}^{3}$.

\begin{tabular}{|l|l|c|}
\hline no. & Material & Weight $(\mathrm{kg})$ \\
\hline 1 & Cement & 400 \\
\hline 2 & Fine aggregate & 740 \\
\hline 3 & Course aggregate & 990 \\
\hline 4 & Water & 180 \\
\hline 5 & Superplasticizer & 0.45 \\
\hline
\end{tabular}

\subsection{Self-compacting concrete SCC}

The laboratory mixing used in this work was according to Emborg [11] and modified by Al-Jabiri [12] for selfcompacting concrete. Table (3) presents the quantities by weight for material used per cubic meter of this mix.

Table 3. Mix Properties for SCC/m3.

\begin{tabular}{|l|l|c|}
\hline no. & Material & Weight $(\mathrm{kg})$ \\
\hline 1 & Cement & 400 \\
\hline 2 & Fine aggregate & 797 \\
\hline 3 & Course aggregate & 767 \\
\hline 4 & Limestone powder & 170 \\
\hline 5 & Water & 180 \\
\hline 6 & Superplasticizer & 4.9 \\
\hline
\end{tabular}




\section{Fresh SCC tests}

SCC is approached on the ability to flow under own weight without any vibration and the ability to gain the homogeneity without any segregation of aggregate. Slump flow, V-Funnel and L-box tests are done to show the fresh properties of SCC. All results were within Specifications.

\section{Casting and curing of HC specimens}

All columns were cast and cured in the laboratory. The Steel mould was containing 2 parts of half circular section and fastens to the base plate with bolts. Then a steel tube with dimeter equal to the inner diameter of the experimental works was fastening inside the steel mould. 6 bars with diameter $8 \mathrm{~mm}$ was used as longitudinal reinforcement and bar with diameter $6 \mathrm{~mm}$ was used as stirrup with spacing $100 \mathrm{~mm}$. At first the outer material was casting and the inner material cast later.

The curing of the specimens was done by submerge the specimen in the water poll for 28 days. Six cubes and six cylinders were also cast and cured with same procedure. Figures (2, 3, 4 and 5) show the preparation of the specimens and Table (4) present the properties of $\mathrm{NC}$ and SCC mixes.

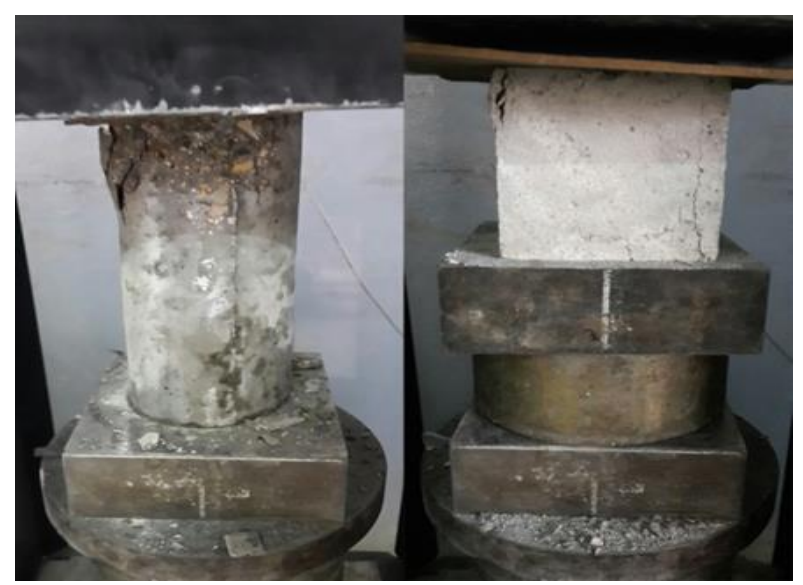

Fig. 2. Cylinder and Cubic specimens under compressive strength tests.

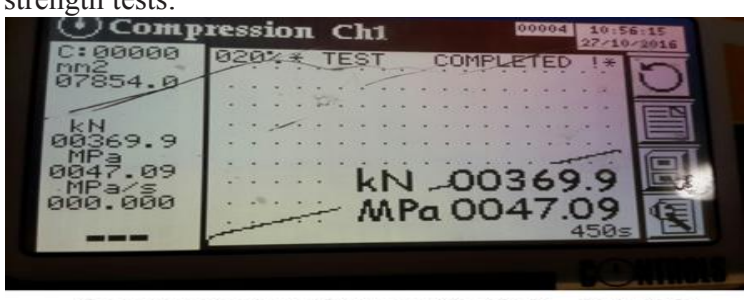

Compression Strength (fc') for NC

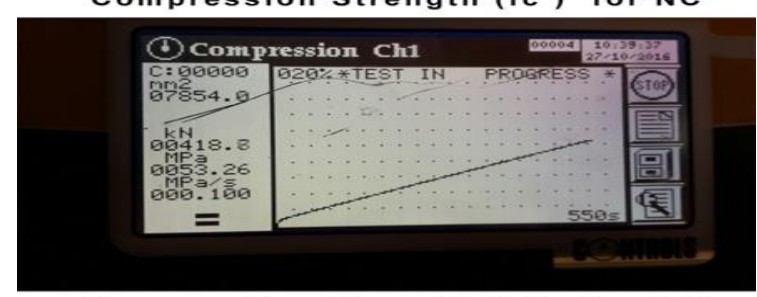

Compression Strength (fc') for SCC

Fig. 3. Results of compressive strength tests for NC and SCC.
Table 4: NC and SCC Properties

\begin{tabular}{|c|c|c|c|}
\hline Type & $\mathrm{fc}^{\prime}(\mathrm{Mpa})$ & $\mathrm{ft}(\mathrm{Mpa})$ & $\mathrm{fr}(\mathrm{Mpa})$ \\
\hline NC & 47 & 3.45 & 4.25 \\
\hline SCC & 53 & 3.65 & 4.5 \\
\hline
\end{tabular}

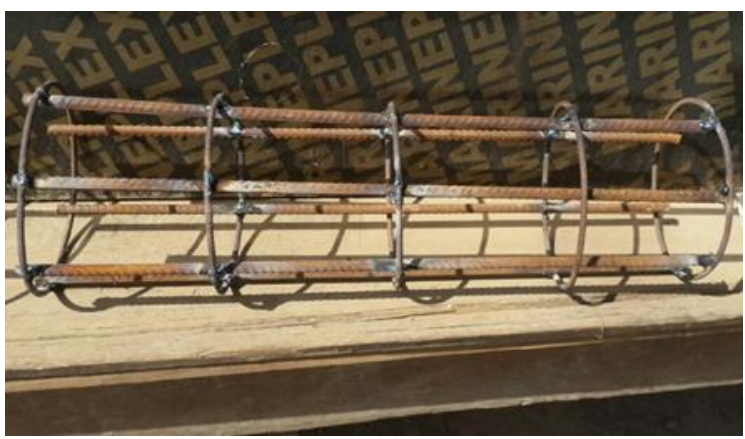

Fig. 4. Reinforcement Details of the columns.

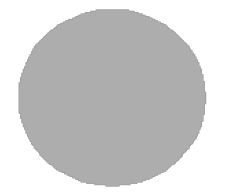

C-NC150-SCC00

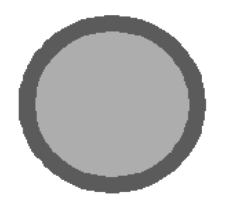

C-NC125-SCC25

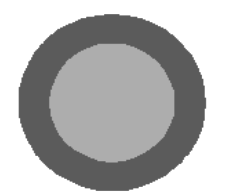

C-NC100-SCC50

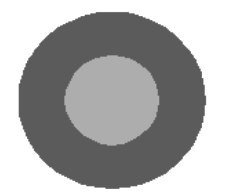

$\mathrm{C}-\mathrm{NC} 75-\mathrm{SCC} 75$

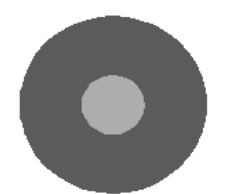

C-NC50-SCC 100

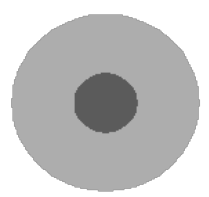

C-SSC $50-\mathrm{NCC} 100$

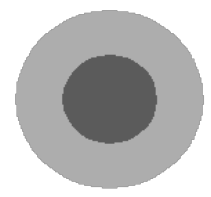

C-SCC75-NC75

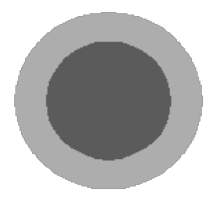

C-SCC100-NC50

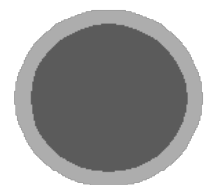

C-SCC $125-\mathrm{NC} 25$

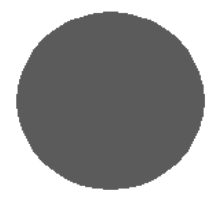

C-SCC $150-\mathrm{NC} 00$

$\mathrm{SCC}$
Fig. 5. HC Columns Details. 


\section{Results and discussion}

Respecting to the experimental works the ten specimens were tested under uniaxial compressive loadings. Table (5) shows the summary of the experimental results.

Table 5: Summary of experimental test results

\begin{tabular}{|c|l|c|c|}
\hline no. & $\begin{array}{c}\text { Column } \\
\text { designation }\end{array}$ & $\begin{array}{c}\text { Ultimate } \\
\text { Load } \\
(\mathrm{kN})\end{array}$ & $\begin{array}{c}\text { Axial Strains } \\
\text { at Ultimate } \\
\text { Load }\end{array}$ \\
\hline 1 & C-NC150-SCC0 & 281 & 0.00063 \\
\hline 2 & C-NC125-SCC25 & 320 & 0.00064 \\
\hline 3 & C-NC100-SCC50 & 354 & 0.00066 \\
\hline 4 & C-NC75-SCC75 & 405 & 0.00072 \\
\hline 5 & C-NC50-SCC100 & 480 & 0.00089 \\
\hline 6 & C-SCC50-NC100 & 503 & 0.00120 \\
\hline 7 & C-SCC75-NC75 & 532 & 0.00085 \\
\hline 8 & C-SCC100-NC50 & 550 & 0.00075 \\
\hline 9 & C-SCC125-NC25 & 573 & 0.00069 \\
\hline 10 & C-SCC150-NC0 & 605 & 0.00062 \\
\hline
\end{tabular}

A study of the structural behaviour of HCC is conducted, the effect of SCC to NC ratio on the axial strength of the column is considered. All columns were failed in compression mode of failure, figures $(6,7$, and 8$)$.

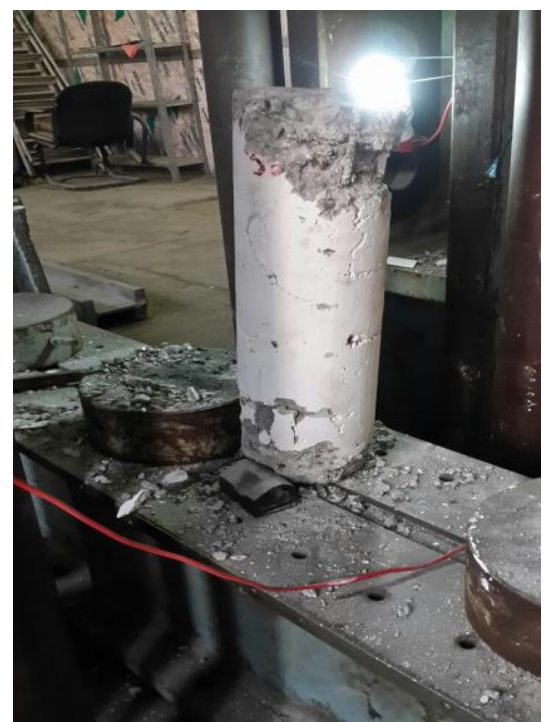

Fig. 6. Failure of Column C-SCC50-NC100

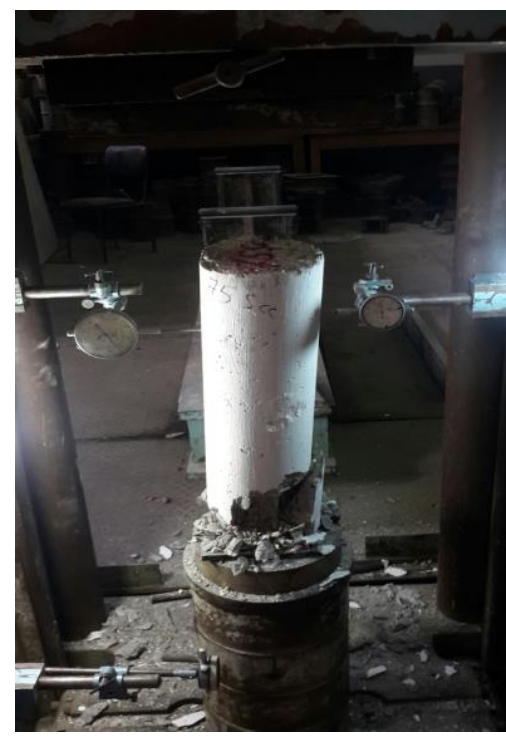

Fig. 7. Failure of Column C-SCC75-NC75

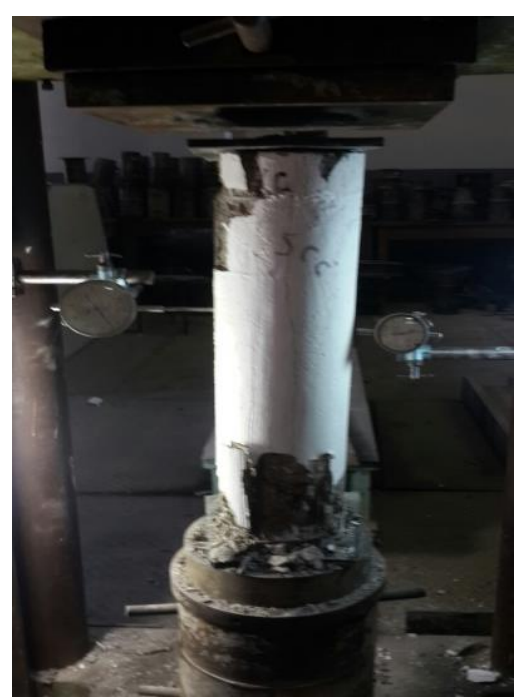

Fig. 8. Failure of Column C-SCC150-NC00

Figures from (9 to 18) show the relationship between the loading and the axial deformation in the columns.

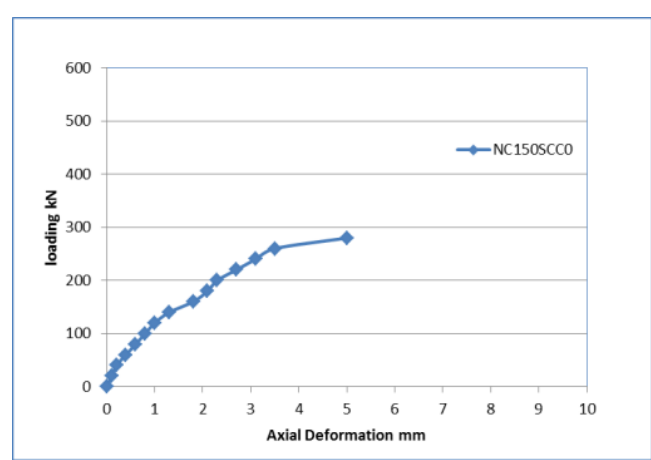

Fig. 9. Load-deformation curve for C-NC150-SCC0. 


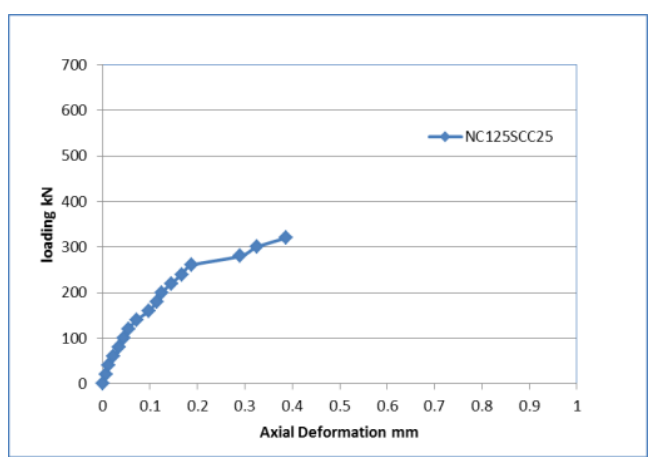

Fig. 10. Load-Deformation curve for C-NC125-SCC25.

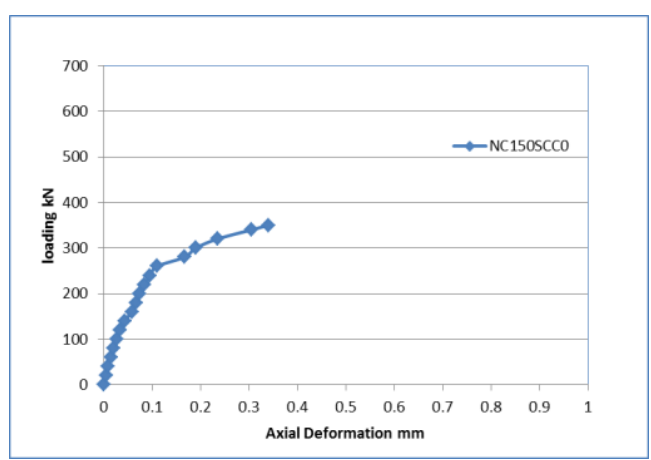

Fig. 11. Load-Deformation curve for C-NC100-SCC50.

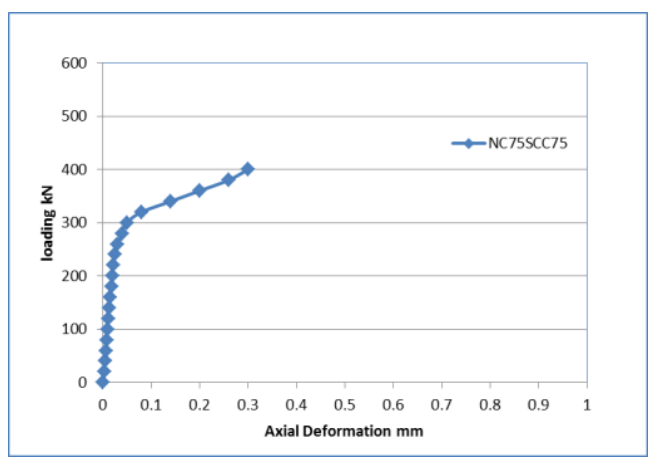

Fig. 12. Load-Deformation curve for C-NC75-SCC75.

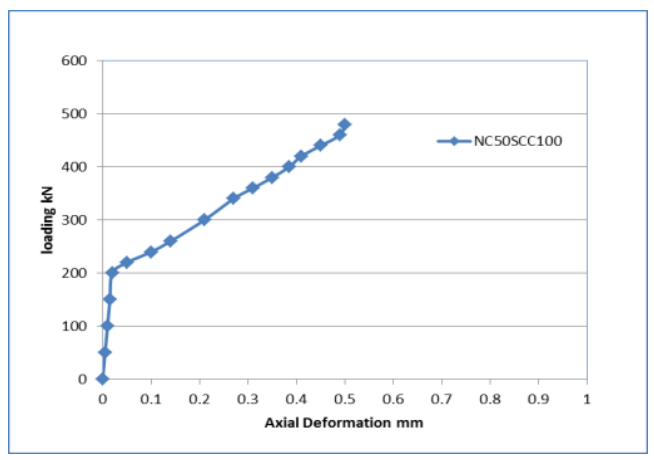

Fig. 13. Load-Deformation curve for C-NC50-SCC100.

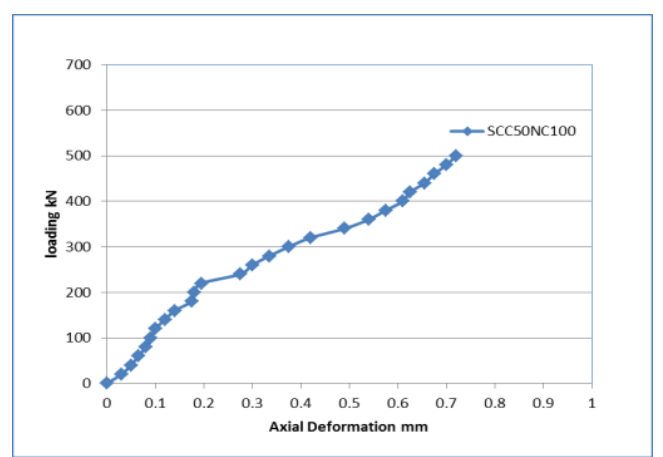

Fig. 14. Load-Deformation curve for C-SCC50-NC100.

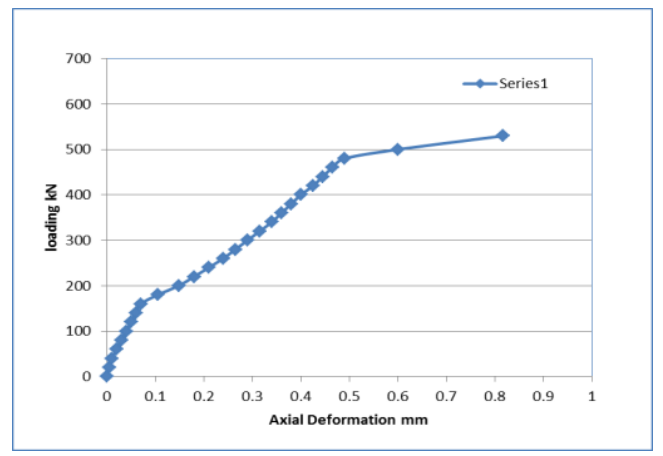

Fig. 15. Load-Deformation curve for C-SCC75-NC75.

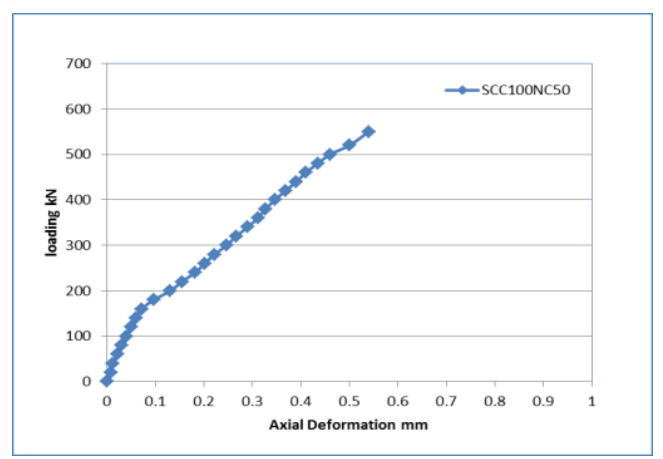

Fig. 16. Load-Deformation curve for C-SCC100-NC50.

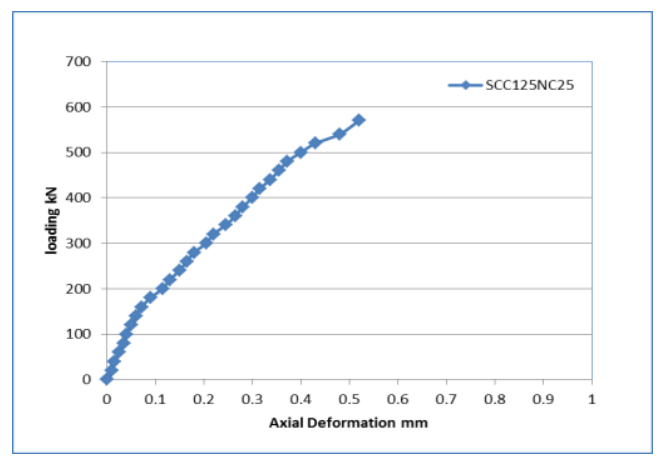

Fig. 17. Load-Deformation curve for C-SCC125-NC25. 


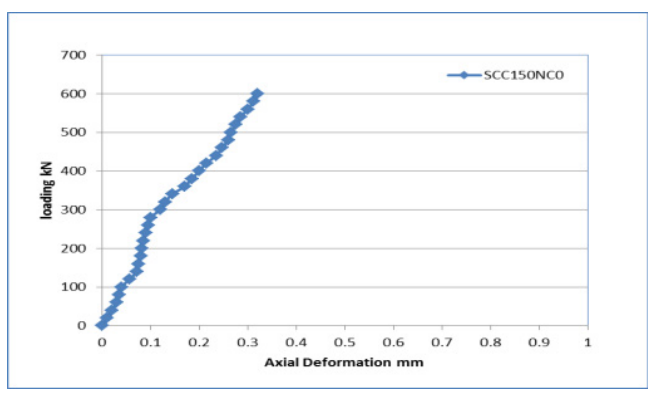

Fig. 18. Load-Deformation curve for C-SCC150-NC0.

\subsection{Effect of SCC/NC ratio on HCC under axial compressing loads}

\subsubsection{Group 1 (NC inner and SCC outer)}

As the ratio of inner diameter to outer diameter (Di/Do) decreased, the load capacity of column increased from $281 \mathrm{kN}$ to $480 \mathrm{kN}$ and the axial deformation was increase also from 0.00063 to 0.00089 as shown in figure (19).

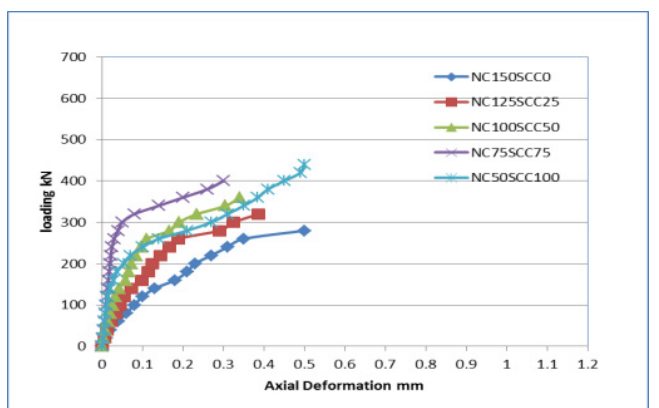

Fig. 19. Load-Deformation curve for GROUP 1.

\subsubsection{Group 2 (SCC inner and NC outer)}

As the ratio of inner diameter to outer diameter (Di/Do) increase, the load capacity of column was increased from $503 \mathrm{kN}$ to $605 \mathrm{kN}$ and the axial deformation was decreased from 0.0012 to 0.00062 , as shown in figure (20).

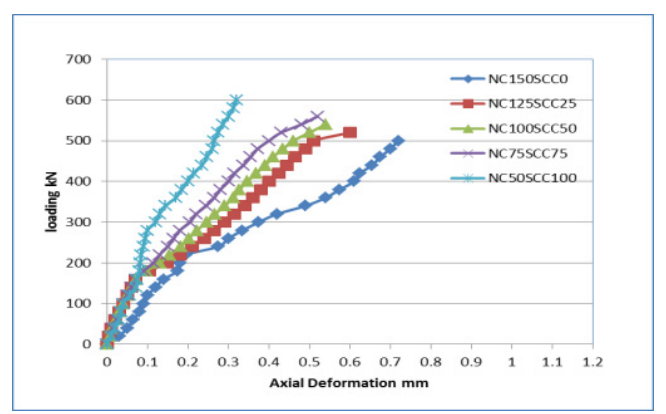

Fig. 20. Load-Deformation curve for GROUP 2.

\subsubsection{Group 3 (Same ratio of Di/Do)}

For the same ratio of inner diameter to outer diameter (Di/Do) for NCC and SCC , the load capacity of column was increased from $354 \mathrm{kN}$ to $550 \mathrm{kN}$ and the axial deformation also increased from 0.00066 to 0.00075 .
The load capacity of column was increased from $281 \mathrm{kN}$ to $605 \mathrm{kN}$ when you change it from fully NC to fully SCC and the axial deformation almost equal

\section{Conclusions}

In this study, the experiment investigation of behaviour of Hybrid Concrete Column under axial compressing loads. The testing of specimens considers the effect of outer to inner diameter ratio on the capacity of the columns.

The experimental program yields following conclusions: 1. All columns were failed in compression mode of failure.

2. The load capacity of column was increased $70 \%$ when the NCC inner diameter decrease and SCC outer dimeter increased.

3 . The load capacity of column was increased $20 \%$ when the SCC inner diameter decrease and $\mathrm{NC}$ outer dimeter increased.

4. it's better to use SCC as outer material because the its work as confinement layer and increasing of load capacity compared with control column.

\section{References}

1. Hsien-Kuang Liu, Nyan-Hwa Tai, Zhi-Cheng Chen. Composite Part B, 1999.M. Ben Rabha, M.F. Boujmil, M. Saadoun, B. Bessaïs, Eur. Phys. J. Appl. Phys. (to be published)

2. Nyan-Hwa Tai, Hsien-Kuang Liu, Zhi-Cheng Chen. Polymer composite, 1999.

3. Elchalakani M ; Zhao XL, and Grzebieta RH. ThinWallStruct.;40(5) :415-41,2002.

4. Tomii, M.proceedings of the Third International Conference on Steel-Concrte Composite Structures, 26-29 Septem ber, Fukuoka, Japan, 39-67, 1991.

5. Wei, S., Mau, S. T., Vipulanadan, C. and Mantrala, and S.K. J. Struct. Eng. ASCE, Vol. 121(12), 18061814, 1995.

6. Iraqi Specifications No. (5), for Portland Cement, 1984.

7. ASTM-C33-03, ASTM International, 2003.

8. EFNARC, European Federation Dedicated To Specialist Construction Chemicals and Concrete Systems, 2005.

9. ASTM-C494-05ASTM International, 2005.

10. Neville, A.M., Fifth and Final Edtion, Wiley, New York and Longmont, London, 844, 2010.

11. Emborg, M., Final Report of Task 8.1, Betongindustri AB, Birte EuRam, Sweeden, 2000.

12. Al-Jabri, L. A., M.Sc. Thesis, Al-Mustansirya University, Baghdad, Iraq, 2005. 